\title{
An Economic Assessment of Energy Poverty and Households Welfare in Ghana
}

\author{
Kwame Yeboah $^{1} \quad$ Edmund Obeng Amaning ${ }^{2^{*}} \quad$ Illiasu Zakaria $^{3} \quad$ Caleb Kwasi Owusu $^{4}$ \\ 1. Energy Economist/Researcher \\ 2. Consultant/Researcher, PO box 662, Madina-Accra, Ghana \\ 3.Nestle Ghana ltd, Accra-Ghana \\ 4.Ghana National Gas Company Ltd, Accra-Ghana \\ Corresponding author: edmundobeng19@gmail.com
}

\begin{abstract}
This study sought to investigate the effects of household socio-economic factors on energy poverty in Ghana. Strong evidence points to the fact that energy is a driver of economic growth, hence, the presence of energy poverty is a major barrier to achieving the development objectives of any country. A binomial logistic model was used to analyse the effects of parametric factors on energy poverty. Data of 16,048 households from the Ghana Living Standards Survey 6, a nationally representative survey, served as the basis for the logistics analysis. The results showed that the energy poverty rate in Ghana stands at 38\% and households spend around $22 \%$ of income on modern energy forms. In addition, energy poverty is more prevalent in rural areas with them being 5.7 times more likely to be energy poor. Also, the results indicated that determinants including age and household size had a negative effect on energy poverty while a higher level of education, income, and welfare had non-decreasing effects on energy poverty. The study concludes that a high welfare level reduces the likelihood that a household is energy poor. To close the disparity between the rural and urban areas with regards to energy access, development of off-grid energy schemes should be implemented largely in rural areas.
\end{abstract}

Keywords: Energy Stacking, Logistic Regression, Energy Poverty, Households Welfare.

DOI: $10.7176 / \mathrm{JESD} / 11-16-01$

Publication date:August $31^{\text {st }} 2020$

\section{Introduction}

Energy plays a key role as an input for the production of goods and services necessary for satisfying needs and wants of microeconomic actors and also ensuring human welfare. Due to the importance of energy in economic development, the nature of the energy system is critical to sustainable development and growth of a country. Research has shown that the global energy sector faces three main challenges i.e. climate change, security of supply and energy poverty, (Birol, 2007; González-Eguino, 2015). Extensive literature and analysis have been undertaking for the first two challenges, however, energy poverty has received less attention despite its influence on millions of lives of people. The concept of energy poverty examines the nexus between energy access (therefore its consumption) and economic development. Energy is a key driver for economic activity from transportation to mining, healthcare to education, electricity production, services provision etc. As such access to energy-efficient, sustainable and affordable forms of energy has a high impact on economic activity. Energy poverty has several different definitions, however, the fundamental thread between these definitions is the issues of access and equity. For instance, Sovacool and Drupady (2012) defined it as "lack of access to electricity and dependence on solid biomass fuels for cooking and heating", whiles Reddy (2000) defined it "as an absence of sufficient choice in accessing adequate, affordable, reliable, high-quality, safe, and environmentally benign energy services to support economic and human development". Other researchers have also defined energy poverty as the "inability to purchase affordable warmth" (Bouzarovski, 2017). These definitions point to reliability and quality of access to energy services necessary to carry out basic need functions and also sustainable development.

In recent times, increasing access to modern forms of energy such as electricity is seen as a way to dealing with the challenges presented by energy poverty and this has been at the forefront of energy debates and dialogues. Modern forms of energy are especially important because it has far-reaching effects and implications for poverty alleviation (Cabraal, Barnes, \& Agarwal, 2005; Pachauri \& Spreng, 2003). Globally, an estimated 1.1 billion people do not have access to electricity with the majority of this number found in developing economies with subSaharan Africa alone accounts for 558 million of the total (International Energy Agency, 2017; World Bank, 2016). The populations in the sub-Saharan region without electricity access rely heavily on biomass as their principal means for the provision of domestic energy needs. This phenomena limits economic opportunities for these population groups as well as creating health and environmental challenges (Pradeep, Alois, \& Lugmayr, 2016; Sovacool \& Drupady, 2012).

\subsection{Statement of problem}

Literature on energy poverty is expansive, especially in high-income countries but in Ghana, studies have addressed issues of energy demand and electricity access. However, in the Ghanaian context, very little empirical 
literature research exist for energy poverty and also, there are knowledge gaps that not addressed in literature with respect to (i) the extent and severity of energy poverty (ii) the relationship between demographic factors and energy poverty amongst households in developing countries (iii) affordability, sustainability and reliability of energy access in sub-Saharan Africa.

This study, therefore, seeks to cover gaps in literature that relate to understanding the extent and relationship between factors affecting energy poverty. To solve the challenges needed to achieve sustainable economic development, energy poverty has to be addressed and this means that policy on energy should be supported with comprehensive and extensively researched literature and information on the extent and severity of energy poverty on households.

\subsection{Objectives of the study}

Generally, this study seeks to investigate the effects of socio-economic factors on energy poverty in households in Ghana. More specifically, the study intends:

i. To establish appropriate indicators for measuring energy poverty in Ghana.

ii. To evaluate the economic relationship between household energy consumption and socio-economic characteristics of households.

iii. To examine the economic welfare implications of energy poverty on households.

\subsection{Research questions}

i. What are the indicators for measuring energy poverty in Ghana?

ii. What is the relationship between household energy consumption and socio-economic characteristics of households?

iii. What are the economic welfare implications of energy poverty on households?

\subsection{Significance of the study}

The study seeks to contribute to the methodological discussion on energy poverty by first describing the severity and extent of energy poverty in Ghanaian households. Also, it seeks to help identify economic welfare linkages and its policy implications for planning for sustainable development.

Also, the study intends to develop clear indicators for holistically measuring energy poverty in low to middle income countries. This point arises because current studies examine issues with access to modern energies forms in developing countries, however, they do not outline indicators that would enable cross-country comparisons for measuring energy poverty levels. It is relatively easy to compare poverty across and within countries based on absolute relative poverty mechanisms, but there are no clear-cut ways to measure energy poverty in many lowincome countries.

\section{LITERATURE REVIEW}

\subsection{Theoretical review}

The main theoretical frameworks are the energy transition theories: energy ladder and energy stacking. They identify the hypothesis that serves as an anchor for energy consumption, poverty and access to energy services.

\subsubsection{Energy transition theories}

Literature on energy poverty agrees fundamentally on the importance of the transition from traditional biomassbased fuel forms to more modern forms of energy. The main theories that underpin energy use and energy transitions are the energy ladder, energy stacking.

\subsubsection{Energy Ladder and Energy Stacking}

The 'energy ladder' theory postulates that as household incomes increases, they transition to cleaner and more efficient forms of energy. This happens as households substitute traditional and 'dirtier' energy forms to more modern energy forms. As such, households 'climb the energy ladder' to higher levels (Hanna \& Oliva, 2015; Hosier \& Dowd, 1987).

According to Schlag and Zuzarte (2008) climbing up the energy is a process in three distinct phases. These phases are manifests as a household desire to use more efficient fuels as their socio-economic status improves. In the first and lowest phase, they use less costly but more pollution solid biomass fuels they can easily access. They then switch to more efficient fuels but significant emission footprint (i.e kerosene and charcoal) in the intermediate phase. The final phase shows a shift to the cleanest forms of fuel (i.e. LPG and electricity). The transitioning process is described in figure 2.1

The implications of this theory are similar to that of neoclassical utility-maximizing consumer that higher the income leads to a marginal rate of substitution towards more sophisticated energy form (Van Der Kroon, Brouwer, \& Van Beukering, 2013). Hence, the higher household incomes in a community, all things being equal, the less prevalent energy poverty. 
Figure 2.1: Energy transition process: energy ladder versus energy stacking

$$
\text { Energy Ladder }
$$

Energy Stack

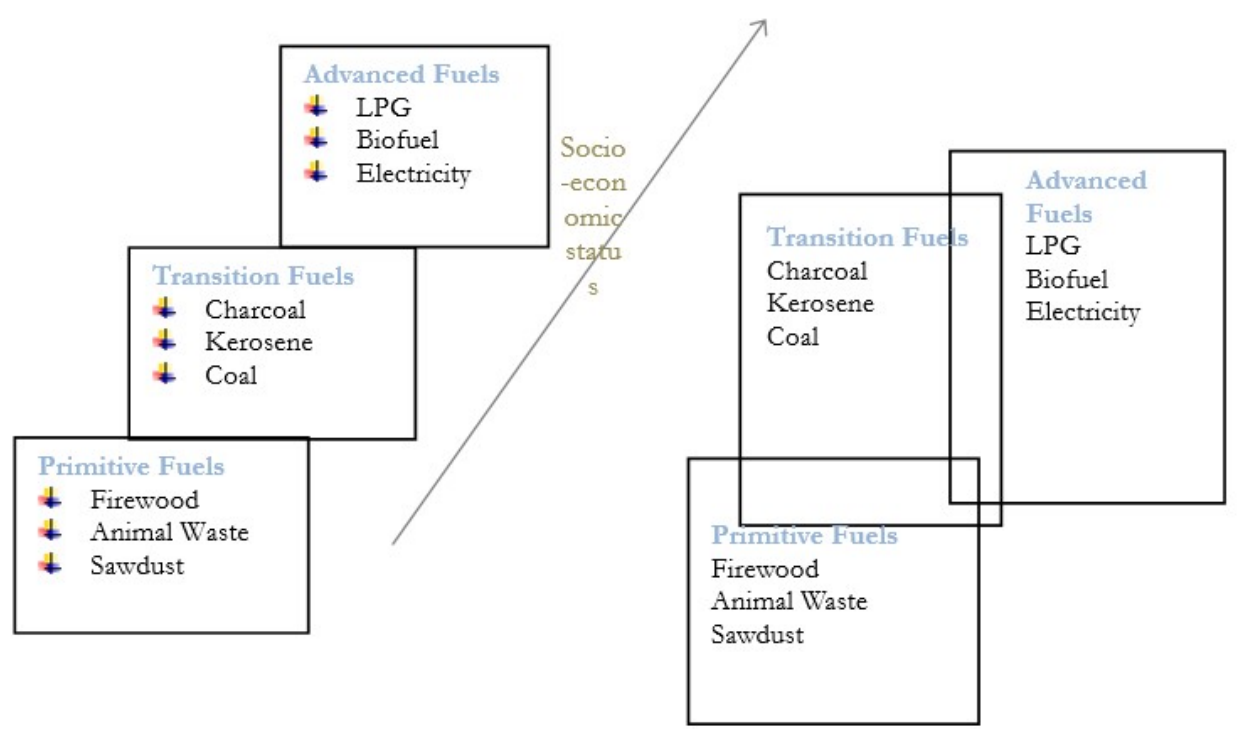

Source: Adapted from Schlag and Zuzarte (2008) and Van Der Kroon, Brouwer and Van Beukering (2013).

\subsubsection{Energy Stacking.}

Unlike the energy ladder theory which suggests perfect substitution with income increases, the energy stacking theory postulates that households use a combination of energy forms that serve as partial rather than perfect substitutes for more traditional fuels (Choumert, Motel, \& Le Roux, 2017; Swarupk \& Rao, 2017; Van Der Kroon et al., 2013). This implies that despite changes in income levels, households may still use less sophisticated energy forms depending on other factors such as location, occupation and convenience (Mirza \& Kemp, 2009).

Hence, in studying energy poverty, energy consumption and income are not the only determinants of a households energy mix. The study's methodology would have to account for the effects of socioeconomic characteristics of households in other to fully explain relationships and causalities of energy poverty (Bhattacharyya, 2006; Mirza \& Kemp, 2009)

In summary, the transition theories highlight the theoretical importance of how rising income and other socioeconomic characteristics influence households energy choice decision. The less desirable qualities of traditional forms of energy render them as inferior goods from a microeconomic perspective. However, as the energy choice theory shows, changes in income alone cannot be used to predict homogenous shifts to energy forms; as a result of the complex interplay of factors affecting households.

\subsection{Empirical review}

The difference between energy poverty and general poverty has been explained by a few scholars. Boardman (1991) believes that energy poverty is different from general poverty as energy poverty can be only be reduced through capital investment while the latter can be reduced by income support alone.

The correlation between energy and some general poverty variables of a household such as income, welfare, health, pollution etc. has been discussed in literature. (Adu, Dramani, \& Oteng-Abayie, 2018; Hanna \& Oliva, 2015; Romero, Linares, \& López, 2018; Ürge-vorsatz \& Herrero, n.d.). There is a consensus that energy poverty has negative effects on the socio-economic well-being of individuals.

Empirically assessments of the energy ladder and energy stacking theories confirm that a move towards cleaner energy reflects improved socio-economic wellbeing. However, there is no consensus on the direction of causality between energy and wellbeing (Hosier and Dowd, 1987; Mensah and Adu, 2015; Choumert, Motel and Le Roux, 2017).

\subsubsection{Energy poverty in Ghana}

The concept of energy poverty in Ghana has been studied to varying degrees especially with most research focusing on access to electricity. Adu, Dramani and Oteng-Abayie (2018), have studied the socio-economic effect of electrification on rural households in Ghana with results suggesting "positive links between rural electrification and welfare".

Household energy choices have been investigated in Ghana using probit models with results showing that shifts in incomes and socio-economic characteristics of households results in a transition to cleaner energy use. However, the transition is faster in richer urban households than in rural households (Karimu et al., 2016; Mensah 


\section{\& Adu, 2015).}

In analysing the impact of household energy use on the environment, the relationship between energy poverty and climate change in Ghana has also being examined revealing that "Ghana is in an energy poverty trap". Hence to effectively mitigate the environmental impacts of energy poverty, efficient cooking and lighting technology should be promoted (Quartey, 2014).

\section{METHODOLOGY}

\subsection{Study design}

To investigate data in order to answer the questions posed by the research, an explanatory research design that uses logistic regression techniques to analyse quantitative cross-sectional data is employed. The data employs the use of secondary cross-sectional data, using only quantitative or binary forms of the data.

\subsection{Data Source}

Data from the last round of the Ghana Living Standards Survey (GLSS 6), a nationally representative survey that collects detailed information on households with each round providing snapshots of living conditions at each stage of the development process. Based on the proportional allocation of the population in the 10 administrative regions of Ghana, census Enumeration Areas (EAs) are derived to serve as the primary sampling units (PSU's) while households within the individual EAs constituted the secondary sampling units (SSU's or households). Each PSU is further divided into urban and rural, based on the locality of residence.

GLSS 6 uses a two-stage stratified sampling method. A total of 1200 EA's was selected in the initial stage. The second stage involved selecting a total of 15 households per EA, bringing the total number of sample households to 18,000 SSU's out of which $93.18 \%$ (16772 SSU's) was successfully administered. For the study, a total of 16048 valid responses were used leaving out invalid income responses.

\subsubsection{Data Analysis procedures}

To investigate data in order to answer the questions posed by the research, an explanatory research design that uses logistic regression techniques to analyze quantitative cross-sectional data is employed.

\subsection{Model Specification}

A model explaining the energy poverty status of a household against factors that might influence this status is given by:

$\mathrm{E}$ (energy poverty status| income, welfare, employment, location, other factors)

$\Rightarrow E(y \mid$ inc, welfare, educ, emp, loc, age, hhsize $)$.

$\Longrightarrow y=\beta_{0}+\beta_{1}$ inc $+\beta_{2}$ welfare $+\delta_{3}$ educ $+\cdots+\xi_{I}$

Therefore, equation (1b) can be simplified to be

$\Rightarrow y_{i}=\beta_{p} X_{i}+\xi_{I}$.

Where $y_{i}$ is the dependent variable energy status for each household $i . \beta_{p}$ represents the vector of coefficients of all independent variables $X_{i} . \xi_{I}$ is the error term which is a vector of all unobserved variables and it follows a normal distribution for all independent observations $\xi_{I} \mid x \sim N(0,1)$.

Since the dependent variable is a dichotomous (binary dependent) variable that lies between 1 and 0 , that is, whether a household is energy poor or not; we use a logistic regression which is commonly used in predicting functional relationships and outcomes of a binary dependent model (Rodriguez, 2007).

3.3.1 Binomial logit regression

Supposing a linear model where the probability of $y_{i}$ is a linear function of its predictors, we estimate the log odds of energy poverty using logistic regression. The logit model is given by:

$$
\Longrightarrow \operatorname{logit}\left(y_{i}\right)=\beta_{p} X_{i}+\xi_{I}
$$

Where equation (2a) is a logit transformation of equation (1c) given by log-odds

$$
\begin{gathered}
\Rightarrow \operatorname{logit}\left(y_{i}\right)=\ln \left(\frac{y_{i}}{1-y_{i}}\right) \\
\therefore \quad y_{i}=\frac{e^{\beta_{p} X_{i}+\xi_{I}}}{1+e^{\beta p X_{i}+\xi_{I}}}
\end{gathered}
$$

Hence the model assumes that the linear probability model is a function of natural log odds:

$$
\ln \left(\frac{y}{y-1}\right)=\beta_{p} X_{i}+\xi_{I}
$$

\subsection{Definition and measurement of variables}

Variables are chosen to estimate the relationships outlined are defined in Table 3.1. 
Table 3.1: Description of model variables.

\begin{tabular}{|lll|}
\hline Variable & Variable type & Description \\
\hline Dependent Variable & & \\
Energy Status & Binary & $\begin{array}{l}0=\text { non energy poor; } \\
1=\text { energy poor }\end{array}$ \\
Independent Variables & & \\
HH Size & Continuous & \\
Sex of HHH & Binary & $1=$ male; (base) \\
Age of HHH & Continuous & \\
& & $0=$ female \\
Educational level & Categorical & $2=$ secondary; \\
& & $3=$ tertiary; \\
& & $4=$ other \\
$1=$ Rural; \\
Location & Binary & $2=$ Urban (base) \\
& & $0=$ very poor; \\
Poverty level & Categorical & $1=$ poor; \\
Log Income & & $2=$ non poor (base) \\
Employment & Continuous & \\
Log Welfare & Categorical & $0=$ inactive/Other; \\
Log of Modern energy expenditure & $1=$ employed; \\
Source: Auth's & $2=$ unemployed (base) \\
& & \\
\hline
\end{tabular}

Source: Author's construct, 2020

\subsection{4.1 Dependent variable}

The dependent variable which describes energy poverty: energy status, is a dichotomous variable (that is, a nominal variable with only two levels) that shows whether a household is energy poor or not. The variable is based on the working definition of energy poverty and it is derived from a transformation of two variables: household access to electricity and household cooking fuel type.

3.4.2 Measuring energy poverty

Measuring energy poverty involved three main steps. The definition of energy poverty indicates that households without access to either electricity or LPG are classified as energy poor.

First, data on household lighting sources were collected. Households with access to electricity (either through mains or private generators) were given a binary measure of 1: indicating non-energy poor household; all other households (using candles, Torchlight etc.) were recorded as energy poor. The same process was used for household cooking sources with households who use electricity or LPG given a binary measure of 1 and households that use traditional energy forms such as firewood and charcoal were considered as energy poor. In the final step, the results from the first and second step were merged into a single variable with two categories: energy poor and non-energy poor.

\subsubsection{Independent variables}

There are 9 independent variables used in this study ranging from demographics to spatial to economic. Income reports the annual net income of the household over the survey year. For the study, log income (which represents the total household net income after they have been log-transformed), is used.

The welfare index given from the GLSS data is also log-transformed as log welfare for analysis purposes. The log-transformed versions are used to handle to non-linearity in trends in income and welfare in households. Poverty level represents the relative poverty status of a household to national poverty estimates.

Household characteristics such as the location of the household, size of household (HH size), educational level, sex and age of head of household $(\mathrm{HHH})$ is also investigated. the employment level of the household head is also included.

The employment level has been re-categorized from 7 categories in the original data to make it more concise. The new categories concatenate the 1) 'employed' groups [self-employed (Agric \& non-Agric), employee (public and private)], 2) 'inactive' groups (retired and other inactive) and 3) 'unemployed' group.

\subsection{Estimation Strategy}

The analysis empirical follows the following procedural steps. First, a binary logit regression is run to determine the log odds of a household being energy poor as well as estimated the marginal effects of variables on energy poverty status. The logistic regression is applied to separate models (one looking at economic variables only and 
one looking at demographic variables only) to determine which choice variables best predict energy poverty levels of a household. This is evaluated by comparing the log-likelihood results of each of the logit models.

To evaluate the goodness of fit of the model, we use a likelihood ratio test which is transformation invariant and allows for detecting the contribution of individual predictors/variables. The result of the likelihood ratio test is then compared to the Wald test and the pseudo-R-squared for robustness (Pawitan, 2000).

\section{RESULTS AND DISCUSSION}

\subsection{Extent of energy poverty in Ghana}

Energy poverty levels currently stand at $38 \%$ of the population of Ghana based on GLSS 6 data. The interesting find is that energy poverty is a rural problem as rural areas 59\% prevalence of energy poverty amongst households as compared to just $12 \%$ in urban areas. Comparatively, energy poverty levels are much higher than the income poverty level in Ghana which stood at 24.2\% in 2013 (Cooke, Hague, \& McKay, 2016). The energy poverty rate is lower than that of some African countries but pales in comparison to some

For households who use at least one modern energy form, it can be seen that they spend $21.86 \%$ of their gross incomes on household energy consumption alone, implying a significant expenditure which is over and above the $10 \%$ threshold in many countries (Longe, Ouahada, Rimer, Zhu, \& Ferreira, 2015; Thomson, Bouzarovski, \& Snell, 2017).

Table 4.1: Main regression logit model for energy poverty status.

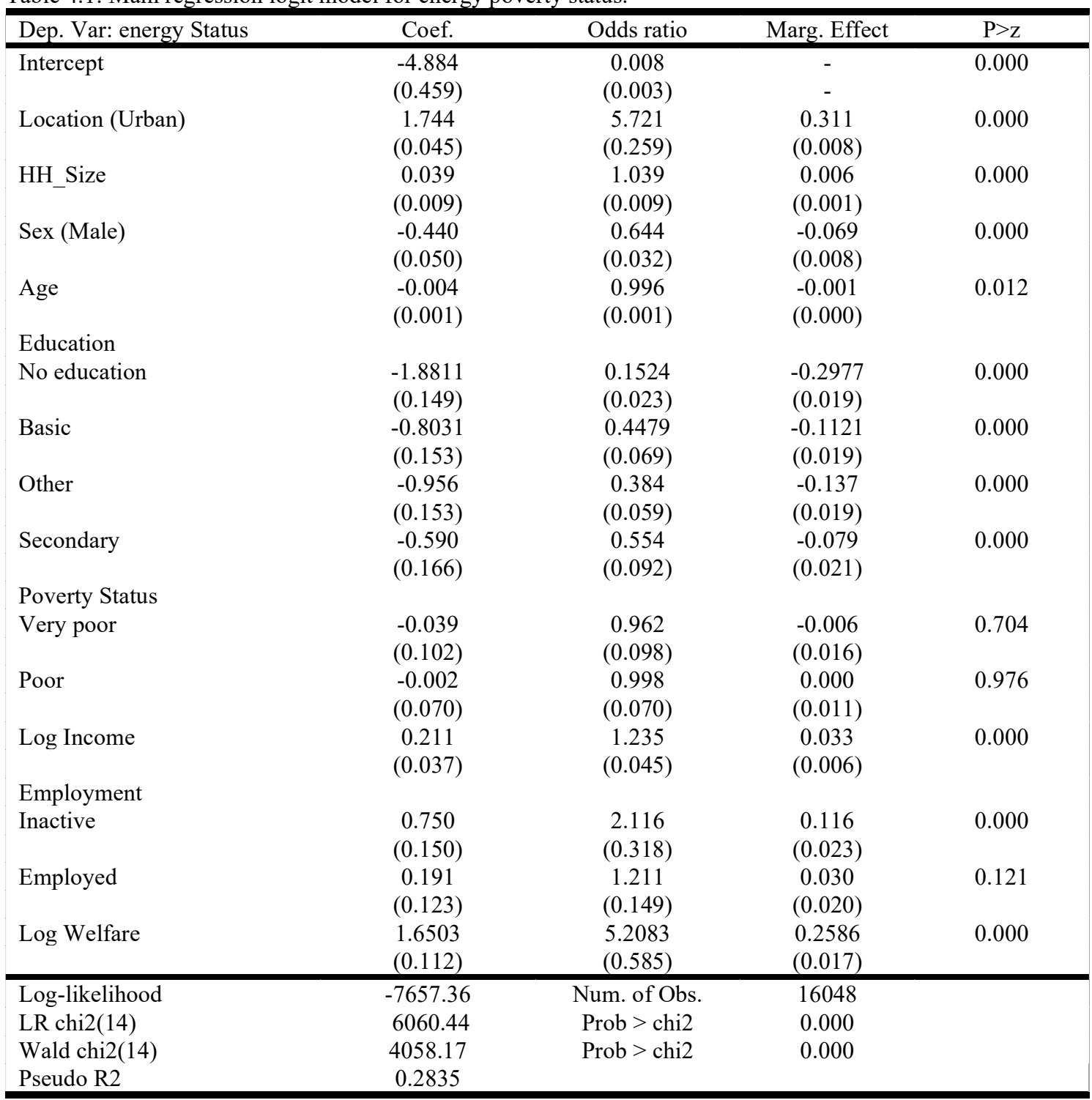

Source: Author's construct from Stata regression, 2020 
The number of valid observations (16048) for the model is less than the number of cases in the original dataset (16772) due to missing cases of income. The likelihood ratio test showed significant $p$-values $(p<0.01)$ which indicates the model was a good fit for the dataset, hence parameters used in the model serve as a good fit for energy poverty status of a household (see appendix A for likelihood ratio test details). The Wald statistic also indicates statistical significance implying a good model fit.

The pseudo-R squared for the unrestricted model is higher than that of the restricted model $(0.284>0.145)$. This also infers the unrestricted model better fits than the restricted model just as in the case of the Wald test and likelihood ratio test (see appendix table B2 for the unrestricted model).

Holding all over variables constant The intercept-only model, the value of the intercept given by coefficient is not statistically significant ( $\mathrm{p}=0.459$ ), however, the log-odds value shows a weak statistical significance. The Log odds is approximately 0 , the expected mean of energy status is zero, which implies that the odds of a household being energy poor cannot be predicted without specific parameters or indicators in the model. These parameters are explored in the next section of this chapter.

\subsection{Predictive indicators for energy poverty in Ghana}

To establish the best indicators for measuring, the results of the log odds and coefficients of the main model is compared with two restricted models: one restricted for demographic and characteristics only (model a: appendix table B3) and one restricted for economic characteristics only (model b: appendix table B4). The predictive power of the models is contrasted in table 4.2 .

Table 4.2: Comparing the predictive power of different regression models.

\begin{tabular}{cccc|}
\hline & Main model & Model a & Model b \\
\hline Log-likelihood & -7657.36 & -8328.2 & -9089.13 \\
LR chi2(14) & 6060.44 & 5961.63 & 3196.9 \\
Prob > chi2 & 0.000 & 0.000 & 0.00 \\
Pseudo R2 & 0.2835 & 0.255 & 0.1496 \\
\hline
\end{tabular}

Source: Authors construct from Stata regression, 2020

The results from Table 4.2, shows that neither the demographic model nor economic models can predict energy poverty as well as the main model. The log-likelihood of the unrestricted model is bigger than that of the two restricted models (main: $-7657.36>$ a: $-8328.20>$ b: -9089.13 ), with the demographic model performing slightly better than the economic only model. Similar inferences can be made from the pseudo-R-square results with model a being closer to the main model than model $\mathrm{b}$. However, it is noted that all 3 logistic regressions show significant results with $\mathrm{p}$-values $<0.05$.

This implies that the demographic indicators (such as household size, education level) alone or economic indicators (such as income and employment) alone cannot best predict energy poverty unless they are combined to give stronger predictive results.

\subsection{Relationship between household socio-economic characteristics and energy poverty}

From Table 4.1, it can be seen that households in urban areas have a higher probability of being non-energy poor than households in rural areas with a coefficient of 1.744 . This relationship is significant with $p=0.045$. The odds ratio that an urban household is not energy poor is 5.7 times higher than a household staying in a rural area. The marginal effect showed that staying in an urban area makes it $31.1 \%(0.311 * 100)$ more likely to be non-energy poor. This finding is consistent with findings in literature that indicate that location plays a major role in energy access that leads to higher energy poverty in rural areas. (Bhattacharyya, 2006; Mirza \& Kemp, 2009)

Male-headed households have less probability of being non-energy poor than female households and this association is statistically significant $(\mathrm{p}=0.05)$. The odds of being energy poor is 0.64 times higher in male-headed households than female-headed households. The marginal effect shows that males are $6.9 \%$ less likely to be nonenergy poor. This result is consistent with findings by Karimu, Mensah and Adu (2016) who describe that femaleled households are more likely to adopt LPG use because of it presents better opportunity cost of time savings and better convenience options for cooking undertaken at home. This is because males are usually less involved in gathering biomass such as firewood, so they less likely to adopt new energy forms.

Household size has a positive significant relationship with being energy non-poor however, this strength of this association is small. An increase in age of household head by one year leads to a $0.1 \%$ increase in the probability that a household would be energy poor. This association is statistically significant with $p=0.01$. This is in contrast with study findings that energy consumption increases with the age of household head and household size (Allen, Janda, \& College, 2006; Räty \& Carlsson-kanyama, 2009). This is attributable to the finding households with older heads have larger household size and lower incomes, all other things being equal, hence they resort to cheaper energy forms to meet cooking and lighting needs.

Also, a larger proportion of households with heads above the 60 age cohort live in rural areas who have a 
significant number of energy-poor households inferring from the earlier results on location households.

The marginal effect of education on energy poverty increases with the level of education of the household head, thus the higher the education, the lower the energy poverty level. With tertiary education, as the base category, the results showed that household heads with no education at were $29.7 \%$ more likely energy poor than tertiary-educated household heads. This gap decreases further with other forms of education where an increase in the level of education led to a $13.7 \%$ likelihood that the household would be energy poor. For households heads with at least some basic education up to middle school, the probability of being energy poor fell by 2 percentage points from $13.7 \%$ to $11.21 \%$ as compared to their counterparts with tertiary education. The difference is smallest between a household head with tertiary education and a household head with secondary education were the gap stands at a $7.9 \%$ difference. The results are all significant for the marginal effects with p-values for no education, other education and basic education being $\mathrm{p}=0.019$ and the $\mathrm{p}$-value for secondary education is $\mathrm{p}=0.021$.

This result clearly show that an increase in the level of education of a household head heavily increases the odds that a household head would adopt modern energy forms and reduce the probability of energy poverty of the household. This is attributable to increased incomes of earned by tertiary educated members, who as discussed earlier, also largely stay in urban areas, hence, rely heavily on the use of modern energy forms such as electricity and LPG. This is line with studies by (Inglesi-Lotz \& del Corral Morales, 2017) which confirm a unidirectional relationship between energy use and education, flowing from education to energy consumption.

The odds of being energy poor increase positively with the level of poverty. The results show that non-poor households have $3.9 \%$ and $0.2 \%$ less likely to be energy poor as compared to households who are very poor and poor respectively. The associations, however, are not statistically strong $(p>0.05)$ for the log odds and coefficients but the marginal effects are significant, although they are very small.

A one unit increase income leads to 1.235 higher odds of being non-energy poor. The association between income and energy poverty shows statistically significant negative with the $\mathrm{p}<0.05$ for the marginal effect and odds. This is consistent with a-priori expectations and literature which indicates that beyond a threshold income, household energy use increases proportionately with income levels, especially with electricity use (Hasan \& Mozumder, 2017). This implies that the more money a household has, the less likely the household would be energy poor.

Households with heads who are unemployed have a less likely probability of being energy rich. This is consistent with research by Link, Axinn and Ghimire, (2012) which indicates that households without employment have a lower opportunity cost for collecting fuelwood, hence, leading to more reliance on traditional energy forms. This relationship, however, is not significant at the $95 \%$ level for the odds ratio and coefficients although significant $(\mathrm{p}=0.01)$ for the inactive segment at the $90 \%$ level. The lack of significance is mainly attributable to the limitation of not being able to capture the level of employment by other household members who might be employed and have a significant influence on household energy choice.

\subsection{Energy poverty and welfare.}

Using Table 4.1 it can be seen that there is a positive and significant association between the marginal effect of welfare levels and energy poverty. Figure 4.1 shows this positive relationship. An increase in welfare by one unit leads to a $25.8 \%$ increase in the probability of a household being energy-rich $(p=0.017)$. This is attributable to the fact that households with higher welfares have higher expenditure thresholds, hence can spend more on the use of electricity and LPG. This is mainly due to the belief that biomass forms of fuels are inferior goods, hence, a welfare increase leads to households maximizing their utilities by shifting away from fuelwood and biomass.

Figure 4.1: Plot of distribution and fit of welfare with energy poverty.

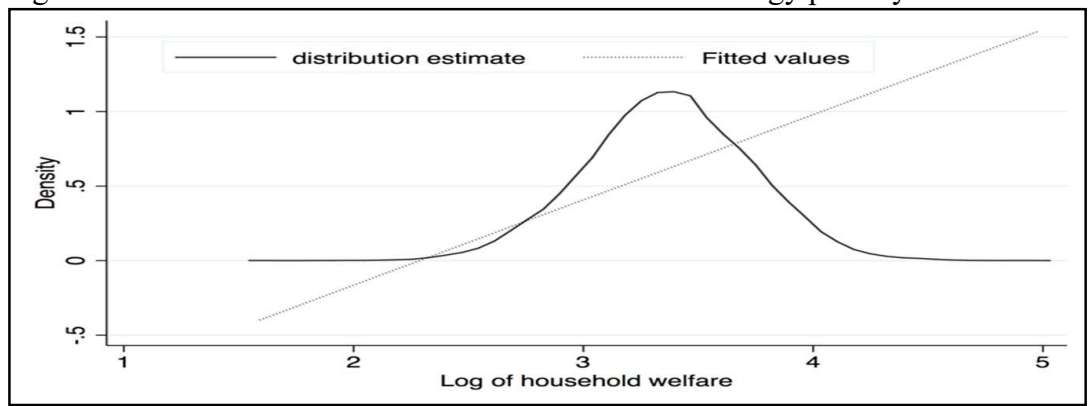

Source: Author's construct, 2020

From the kernel density distribution diagram in Figure 4.1, it can be seen that welfare levels have a normal distribution and welfare fitted values are positively related to energy status. At lower levels of welfare, the probability that the household is energy poor (that is energy Status $=0$ ) is high. As welfare increases, this probabilities shift towards energy poverty reduces towards 1 (energy non-poor). 


\section{Conclusion}

The study attempted to evaluate the effect of household socio-economic characteristics on energy poverty in Ghana. In predicting energy poor households, the study findings showed that demographic indicators especially the location of a household and educational level of a household's head are the key indicators of households probability of being energy poverty. This is consistent with findings in literature. In measuring energy poverty in Ghana, the study concludes that demographic and economic indicators, that is location, educational level of household head, and welfare level of household are important.

The results showed that there is a strong relationship between household energy consumption and socioeconomic characteristics of households. Determinants such as age and household size had a negative effect on energy poverty while a higher level of education, household income, poverty status had non-decreasing effects on energy poverty. The study concludes, in line with the energy ladder theory, that improvement in socio-economic variables of a household reduces energy poverty.

The study revealed lower welfare amongst households in the lower quantiles of energy poverty. Also, there are positive correlations between higher welfare are reduced energy poverty. In energy-rich households, welfare is the biggest driver of energy consumption. The study, therefore, concludes that a high welfare level reduces the likelihood that a household is energy poor.

\section{Policy recommendations}

In reducing energy poverty and enabling households to derive significant gains and benefits associated with modern energy use, the following policy recommendations are made. Firstly, in rolling out energy access programs such as rural electrification initiatives, implementation agencies should focus on females, who according to the literature and the study adopt modern energy faster.

Secondly, initiatives for micro-financing households to use modern energy forms should be promoted by energy conservation and power regulatory agencies. Also, energy education should be carried out extensively in rural areas in addition to subsidies and financing to ensure that households get to understand the benefits of adopting modern energy forms and reducing fuel poverty.

Finally, to close the disparity between the rural and urban areas with regards to energy access, the development of off-grid energy schemes should be implemented largely in rural areas by the electricity providing agencies.

\section{References}

Adu, G., Dramani, J., \& Oteng-Abayie, E. (2018). Powering the powerless: Economic impact of rural electrification in Ghana. IGC, (February). Retrieved from https://www.theigc.org/project/poweringpowerless-economic-impact-rural-electrification-ghana/

Allen, D., Janda, K., \& College, O. (2006). The Effects of Household Characteristics and Energy Use Consciousness on the Effectiveness of Real-Time Energy Use Feedback: A Pilot Study Continuous Feedback : The Next Step In Residential EnergyConservation? Buildings, 1-12.

Bhattacharyya, S. C. (2006). Energy access problem of the poor in India: Is rural electrification a remedy? Energy Policy, 34(18), 3387-3397.

Birol, F. (2007). Energy economics: A place for energy poverty in the agenda? Energy Journal, 28(3), 1-6. https://doi.org/10.5547/ISSN0195-6574-EJ-Vol28-No3-1

Boardman, B. (1991). Fuel Poverty is Different. Policy Studies, 12(4), $30-41$. https://doi.org/10.1080/01442879108423600

Bouzarovski, S. (2017). Energy Poverty: (Dis)Assembling Europe's Infrastructural Divide. Cham: Palgrave Macmillan/Springer. https://doi.org/10.1007/978-3-319-69299-9

Cabraal, R. A., Barnes, D. F., \& Agarwal, S. G. (2005). Productive Uses of Energy for Rural Development. Annual Review of Environment and Resources, $30(1), \quad$ 117-144. https://doi.org/10.1146/annurev.energy.30.050504.144228

Choumert, J., Motel, P. C., \& Le Roux, L. (2017). Energy Ladder or Energy Stacking: a Panel Data Analysis of Tanzanian Households' Energy Choices, (July), 1-42.

Cooke, E., Hague, S., \& McKay, A. (2016). The Ghana Poverty and Inequality Report. Using the 6th Ghana Living Standards Survey.

González-Eguino, M. (2015). Energy poverty: An overview. Renewable and Sustainable Energy Reviews, 47, 377-385. https://doi.org/10.1016/j.rser.2015.03.013

Hanna, R., \& Oliva, P. (2015). Moving up the Energy Ladder: The Effect of an Increase in Economic Well-Being on the Fuel Consumption Choices of the Poor in India. American Economic Review, 105(5), 242-246.

Hasan, S. A., \& Mozumder, P. (2017). Income and energy use in Bangladesh: A household level analysis. Energy Economics, 65, 115-126.

Hosier, R. H., \& Dowd, J. (1987). Household fuel choice in Zimbabwe: An empirical test of the energy ladder 
hypothesis. Resources and Energy, 9(4), 347-361.

Inglesi-Lotz, R., \& del Corral Morales, L. D. (2017). The Effect of Education on a Country's Energy Consumption: Evidence from Developed and Developing Countries. Retrieved from https://ideas.repec.org/p/pre/wpaper/201733.html

International Energy Agency. (2017). WEO-2017 Special Report: Energy Access Outlook.

Karimu, A., Mensah, J. T., \& Adu, G. (2016). Who Adopts LPG as the Main Cooking Fuel and Why? Empirical Evidence on Ghana Based on National Survey. World Development, 85, $43-57$. https://doi.org/10.1016/j.worlddev.2016.05.004

Link, C. F., Axinn, W. G., \& Ghimire, D. J. (2012). Household energy consumption: Community context and the fuelwood transition. Social Science Research, 41(3), 598-611. https://doi.org/10.1016/j.ssresearch.2011.12.007

Longe, O. M., Ouahada, K., Rimer, S., Zhu, H., \& Ferreira, H. C. (2015). Effective energy consumption scheduling in smart homes. Africon 2015.

Mensah, J. T., \& Adu, G. (2015). An empirical analysis of household energy choice in Ghana. Renewable and Sustainable Energy Reviews, 51, 1402-1411. https://doi.org/10.1016/j.rser.2015.07.050

Mirza, B., \& Kemp, R. (2009). Why Rural Rich Remain Energy Poor. United Nations University Working Paper Series, 6(31), 1-28.

Pachauri, S., \& Spreng, D. (2003). Energy Use and Energy Access in Relation to Poverty, (25), 1-20.

Pawitan, Y. (2000). A Reminder of the Fallibility of the Wald Statistic: Likelihood Explanation. The American Statistician, 54(1), 54-56.

Pradeep, M., Alois, P. M., \& Lugmayr, M. (2016). Decentralized power in countries of ECOWAS region: A case study. In L. Guruswamy \& E. Neville (Eds.), International Energy and Poverty: The Emerging Contours (pp. 181-191). Routledge.

Quartey, J. D. (2014). Energy poverty and climate change mitigation in Ghana: An economic assessment. Journal of Economics and Sustainable Development, 5(8), 72-85. Retrieved from http://iiste.org/Journals/index.php/JEDS/article/view/12608

Räty, R., \& Carlsson-kanyama, A. (2009). Comparing energy use by gender, age and income in some European countries. FOI, Swedish Defence Research Agency.

Reddy, A. (2000). Energy and the challenge of Sustainability. In United Nations Development Program (Ed.), World Energy Assessment (p. 506).

Rodriguez, G. (2007). Logit Models for Binary Data (p. Chapter 3). Retrieved from http://data.princeton.edu/wws509/notes/

Romero, J. C., Linares, P., \& López, X. (2018). The policy implications of energy poverty indicators. Energy Policy. https://doi.org/10.1016/j.enpol.2017.12.054

Schlag, N., \& Zuzarte, F. (2008). Market Barriers to Clean Cooking Fuels in Sub-Saharan Africa: A Review of Literature. Fuel, (April), 1-21.

Sovacool, B. K., \& Drupady, I. M. (2012). Energy Access, Poverty, and Development. Surrey: Ashgate Publishing Limited.

Swarupk, V. A., \& Rao, R. (2017). An Econometric Approach to Analysis of Trends and Patterns of Household Fuel Choices in India. Indian Economic Review, 50(1), 105-129.

Thomson, H., Bouzarovski, S., \& Snell, C. (2017). Rethinking the measurement of energy poverty in Europe: A critical analysis of indicators and data. Indoor and Built Environment. https://doi.org/10.1177/1420326X17699260

Van Der Kroon, B., Brouwer, R., \& Van Beukering, P. J. H. (2013). The energy ladder: Theoretical myth or empirical truth? Results from a meta-analysis. Renewable and Sustainable Energy Reviews, 20, 504-513. https://doi.org/10.1016/j.rser.2012.11.045

World Bank. (2016). Access to Electricity (\% of Population). World Bank, 1-11. https://doi.org/10.1017/CBO9781107415324.004 